CORRECTION

\title{
Correction: Expression patterns and prognostic potential of circular RNAs in mantle cell lymphoma: a study of younger patients from the MCL2 and MCL3 clinical trials
}

Mette Dahl (iD, Simon Husby, Christian W. Eskelund, Søren Besenbacher (iD, Søren Fjelstrup, Christophe Côme (iD, Sara Ek (iD, Arne Kolstad, Riikka Räty, Mats Jerkeman (D), Christian H. Geisler, Jørgen Kjems, Lasse S. Kristensen (iD) and Kirsten Grønbæk (iD

(c) The Author(s), under exclusive licence to Springer Nature Limited 2022

Leukemia (2022) 36:1198; https://doi.org/10.1038/s41375-022-01526-z

Correction to: Leukemia https://doi.org/10.1038/s41375-02101311-4, published online 9 July 2021

Following the publication of this article the authors noted an error in the computational formula listed for circSCORE
The correct formula is listed below and has been updated in the article:

$\operatorname{circSCORE}=-0.044 * \log (\operatorname{circANKRD17})+0.245 * \log (\operatorname{circARID1A})$

$+-0.247 * \log (\operatorname{circEXOC6B})+-0.402 * \log ($ FAM13B $)$

$+0.356 * \log (\operatorname{circNCOA2})+-0.146 * \log (\operatorname{circPNN})$

$+-0.413 * \log (\operatorname{circRAB} 11 \mathrm{FIP} 1)+-0.028$

$* \log (\operatorname{circZCCHC6})+-0.105^{*} \log (\operatorname{circZNF609})$ 